\section{REFERENCES}

1. National Health and Medical Research Council. The Australian Immunisation Handbook, 7th edition. Canberra: National Health and Medical Research Council, 2000.

2. Rea MD, Dalton CB, Ebeling PW, Ferguson JK. Pertussis death in the Hunter region of New South Wales [letter]. Med J Aust 2001;175:172-3.

3. Halperin SA, Bortolussi R, Langley JM, Miller B, Eastwood BJ. Seven days of erythromycin estolate is as effective as fourteen days for the treatment of Bordetella pertussis infections. Pediatrics 1997;100:65-71.

4. Poynten IM, Hanlon M, Irwig L, Gilbert GL. Serological diagnosis of pertussis: evaluation of $\operatorname{IgA}$ against whole-cell and specific Bordetella pertussis antigens as markers of recent infection. Epidemiol Infection 2002;128:161-7.

5. Australian Childhood Immunisation Register. Health Insurance Commission, Canberra. Date of processing 30 June 2001.

6. Australian Childhood Immunisation Register. Health Insurance Commission, Canberra. Date of processing 31 December 2001.
7. Torvaldsen S, Simpson JM, McIntyre PB. Effectiveness of pertussis vaccination in New South Wales, Australia, 19968. Eur J Epidemiol 2003;18:63-9.

8. Australian Bureau of Statistics. 1989-90 National Health Survey Children's immunisation, Australia. Catalogue no 4379.0. Release data 9 October 1992. Canberra: Australian Government Printer, 1992.

9. Australian Technical Advisory Group on Immunisation. Draft 8th edition Australian Immunisation Handbook. Canberra: Commonwealth Department of Health and Ageing, October 2002.

10. Hethcote HW. Simulations of pertussis epidemiology in the United States: effects of adult booster vaccinations. Mathematical Biosciences 1999;158:47-73.

11. Physicians and Surgeons of the Principal London Hospital. The Family Physician. Manual of Domestic Medicine. Volume 1, 1884.

\title{
DO VARIATIONS IN PERTUSSIS NOTIFICATIONS REFLECT INCIDENCE OR SURVEILLANCE PRACTICES? A COMPARISON OF INFANT NOTIFICATION RATES AND HOSPITALISATION DATA IN NSW
}

\author{
Siranda Torvaldsen and Peter McIntyre \\ National Centre for Immunisation Research and \\ Surveillance of Vaccine Preventable Diseases \\ University of Sydney, Westmead
}

The incidence of pertussis cannot be directly measured; estimates are generally based on data sources such as notifications, hospitalisations and deaths. However, these data represent only a proportion of the total cases occurring in the community. The accuracy of notification data may vary between states and territories or over time due to different surveillance practices and as new diagnostic tests are introduced. These surveillance issues, and the typical three-to-five-year cycles of pertussis epidemics, make comparisons over time and between states and territories difficult. However, the comparisons should be more valid for hospitalisation data than for notification data, because methods of collecting hospitalisation data are likely to be more uniform. Some variation in incidence by geographical area is to be expected, depending on the timing of the last epidemic and also on geographical differences in past or present pertussis vaccination coverage. If geographical variations in pertussis notifications reflect real variations in pertussis incidence rather than reporting differences, areas with high infant (aged less than 12 months of age) notification rates would be expected to have high infant hospitalisation rates. This article describes and compares the notification and hospitalisation rates in infants for pertussis, by health area, over a period incorporating two pertussis epidemics in NSW.

\section{METHODS}

Medical practitioners and laboratories in NSW are required by legislation to notify the NSW Department of Health, through one of the 17 public health units, of any person who meets the case definition for pertussis. This information is then entered into the Notifiable Diseases Database (NDD). The case definition for pertussis is: ${ }^{1}$

- isolation of Bordetella pertussis from a clinical specimen; or

- elevated Bordetella pertussis specific IgA in serum or Bordetella pertussis antigen in a nasopharyngeal specimen using immunofluorescence, with a history of clinically compatible illness; or

- an illness lasting two weeks or more with one of the following: paroxysms of coughing, inspiratory 'whoop' without other apparent causes, or post-tussive vomiting; or 
- an illness characterised by a cough illness lasting at least two weeks in a patient who is epidemiologically related to a laboratory-confirmed case.

All notified cases of pertussis with dates of onset of disease between 1 July 1993 and 30 June 1999 were extracted from NDD in the Health Outcomes Information Statistical Toolkit (HOIST), NSW Department of Health, in March 2000. SAS for Windows and Excel were used for the analyses. ${ }^{2,3}$

Data on pertussis cases discharged from hospital between July 1993 and June 1999 were extracted from the NSW Department of Health's Inpatient Statistics Collection Online System (ISCOS) by financial year of discharge and age in months on admission, in February 2001. For the period 1993 to June 1998, the International Classification of Diseases code 033 (whooping cough) was used to identify deaths (ICD-9) and hospitalisations (ICD-9-CM). From July 1998 to June 1999 the ICD-10-AM code A37 was used. This code includes codes for Bordetella pertussis (A37.0), Bordetella parapertussis (A37.1) and whooping cough with no organism mentioned (A37.9).

Rates were calculated using Australian Bureau of Statistics (ABS) mid-year estimated resident populations for NSW. For hospitalisation data, the mid-year population estimate for the first half of the financial year was used as the denominator.

\section{RESULTS}

Between July 1993 and June 1999, 721 cases of pertussis in infants were notified, 291 (40 per cent) of whom were recorded on the NDD as being hospitalised. Infants accounted for six per cent of total pertussis notifications. During the same period, there were 949 infants hospitalised with pertussis in the ISCOS, accounting for 61 per cent of total pertussis hospitalisations. Notification and hospitalisation rates peaked in 1993-94 and again in 1997-98 (Figure 1). The notification rate became closer to, but remained less than, the hospitalisation rate over time (Figure 1).

There was considerable variation in hospitalisation and notification rates between the 17 area health services (Table 1). The overall ratio of notifications to hospitalisations for the six-year period was $1: 1.3$, but this ratio varied by health area from 1:0.9 in the Hunter, Northern Rivers, Mid North Coast and Mid Western areas to $1: 2.2$ in South Western Sydney. For each of the metropolitan areas, except the Hunter, the total number of hospitalisations in the $0-11$ months age group was greater than the number of notifications for the same age group. This was also the case in half the rural areas. The Hunter

\section{FIGURE 1}

NOTIFICATION AND HOSPITALISATION RATES FOR PERTUSSIS IN INFANTS, BY FINANCIAL YEAR OF ONSET-DISCHARGE, NSW, JULY 1993-JUNE 1999

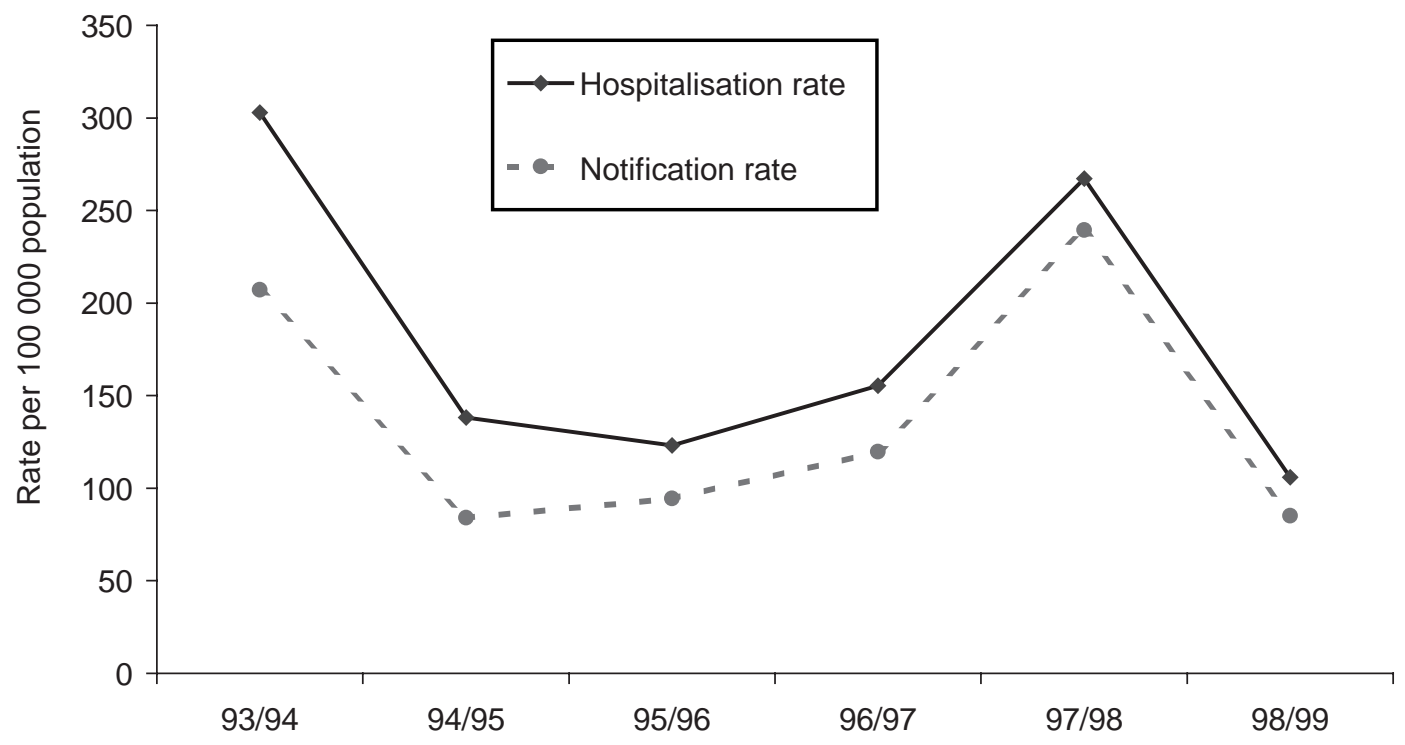

Financial year of onset-discharge

Source: Notifiable Diseases Database (HOIST); Inpatient Statistics Collection Online System (ISCOS), Information Management Directorate. NSW Department of Health; and the Australian Bureau of Statistics (ABS). 
TABLE 1

NUMBER OF NOTIFICATIONS AND HOSPITALISATIONS FOR PERTUSSIS IN INFANTS, RATIOS OF NOTIFICATIONS TO HOSPITALISATIONS AND AVERAGE ANNUAL RATES PER 100,000 POPULATION AGED 0-11 MONTHS BY HEALTH AREA AND FINANCIAL YEARS OF ONSET-DISCHARGE, NSW, JULY 1993-JUNE 1999

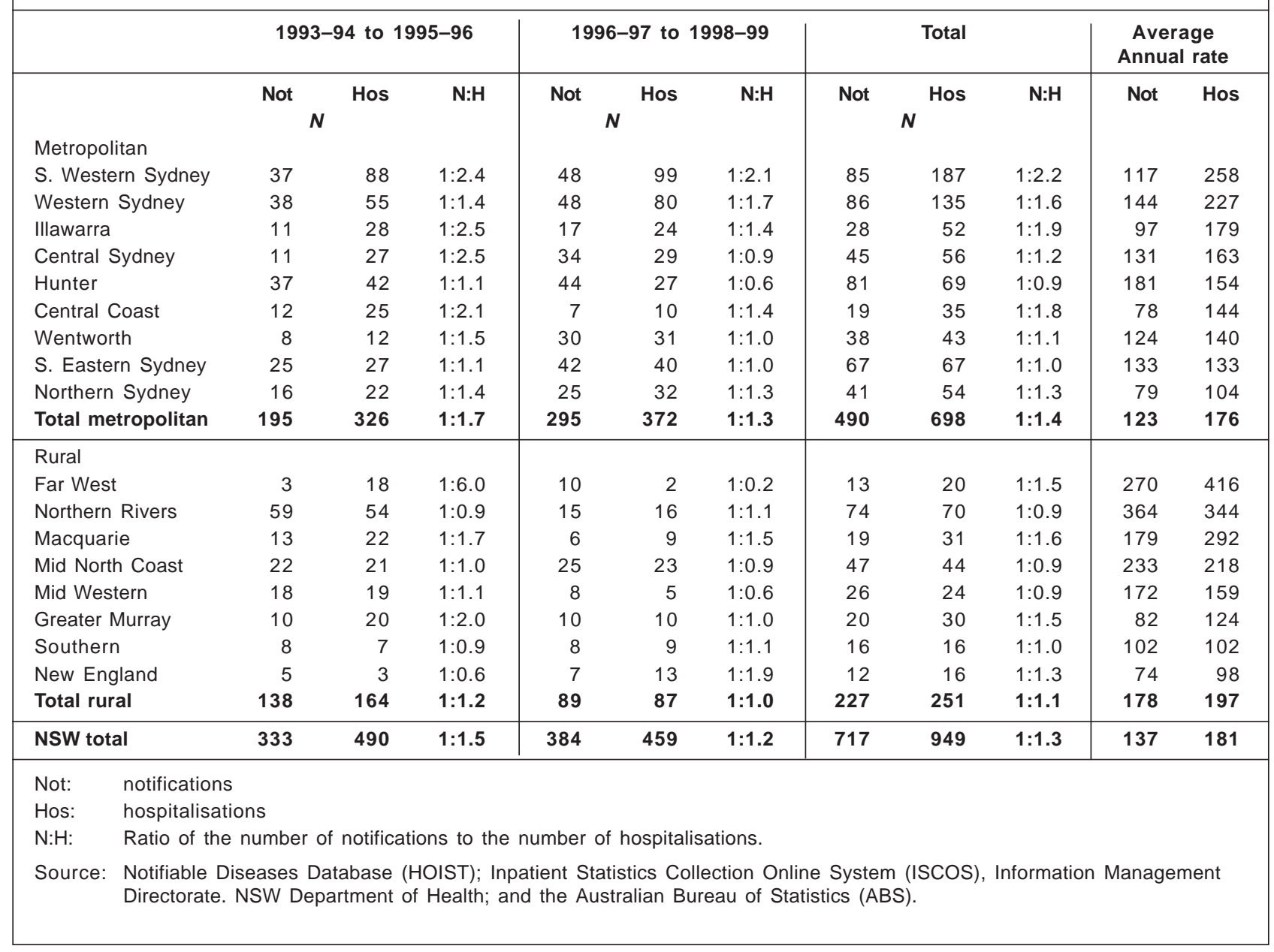

and Central Coast Areas, which are adjacent, had similar hospitalisation rates but their notification rates differed.

\section{DISCUSSION}

This comparison of infant notification and hospitalisation data highlights the extent of under-notification and the degree of variation between the health areas in notification and hospitalisation rates. Although only a proportion of infant pertussis cases (those with severe disease) are hospitalised, the number of hospitalisations exceeds the number of notifications by 32 per cent. This is similar to the pattern seen nationally, ${ }^{4}$ and in New Zealand. ${ }^{5}$ As the infant notification rate is lower than the hospitalisation rate, it must underestimate incidence considerably. Pertussis is more severe in infants compared with other age groups, hence the need for accurate data to target infants in pertussis control programs. In order to better control infant pertussis it would be useful to have a measure of incidence. Hospitalisation data are less subject to variations in reporting practices than notification data and therefore may be more useful for monitoring trends in incidence among infants than notification data. Notifications of pertussis by medical practitioners, as opposed to laboratories, have been shown to be low in South Eastern Sydney and the Northern Rivers Health Areas. ${ }^{6,78}$ In addition, a recent survey of symptoms consistent with pertussis in Western Sydney children found the parent-reported rate of doctor-diagnosed pertussis in the previous 12 months to be 12 times greater than notifications. ${ }^{9}$

The extent to which the differences in notification rates between areas reflect differences in incidence versus differences in diagnostic and notification practices is difficult to determine using notification data alone. However, the comparison of infant notifications and hospitalisations in each area over the same time period provides some insights. The health area with the highest average annual notification rate was Northern Rivers. Northern Rivers also had the second highest 
hospitalisation rate (the highest was the Far West, but this was calculated on very few cases) suggesting that pertussis incidence in this area is higher than in other areas. This is likely to be related to vaccination coverage. Northern Rivers has the lowest pertussis vaccination coverage of any area health service in NSW, with only 81 per cent of children aged 12 months being recorded on the Australian Childhood Immunisation Register as having received three doses of a pertussis-containing vaccine in $1999 .{ }^{10} \mathrm{~A}$ wide range in notification rates by geographical area has also been observed in Victoria. ${ }^{11}$

The Hunter had a much higher notification rate than the geographically adjacent Central Coast, with the average annual infant notification rate in the Hunter being 230 per cent higher than that in the Central Coast. In contrast, the average annual infant hospitalisation rate was only seven per cent higher in the Hunter, suggesting that the degree of under-reporting is greater in the Central Coast than in the Hunter. The ratios of notifications to hospitalisations for the health areas give an indication of the relative extent of under-reporting in each health area. Some health areas may more actively seek cases, particularly if they are experiencing an outbreak. Some of the differences in ratios may be due to doctors and/or laboratories in the area being more or less willing to notify. This may have more of an influence on notification rates in less densely populated areas where there are fewer doctors or laboratories.

\section{CONCLUSION}

The epidemic pattern shown by notification and hospitalisation rates over time was very similar, suggesting that this reflects real variations in incidence. During the 1997-1998 pertussis epidemic, increased numbers of both notifications and hospitalisations occurred in almost all metropolitan health areas and some of the rural areas. However, only some of the geographical variations in notification rates correlate with hospitalisation patterns, suggesting that some of these are due to variations in surveillance practices. Although less timely, hospitalisation data are likely to be more reliable as a means of tracking infant pertussis and the effects of vaccination coverage over time.

\section{REFERENCES}

1. National Health and Medical Research Council. Surveillance case definitions. Canberra: Australian Government Publishing Service, 1994.

2. SAS Institute Inc. The SAS System for Windows. Cary, NC: SAS Institute Inc., 1996.

3. Microsoft Corporation. Microsoft ${ }^{\circledR}$ Excel 97: INSO Corporation, 1993.

4. McIntyre P, Amin J, Gidding H, Hull B, Torvaldsen S, Tucker $\mathrm{A}$, et al. Vaccine preventable diseases and vaccination coverage in Australia, 1993-1998. Commun Dis Intell 2000;24 Suppl:S1-S83.

5. Blakely T, Mansoor O, Baker M. The 1996 pertussis epidemic in New Zealand: descriptive epidemiology. $N$ Z Med J 1999;112:30-3.

6. Rushworth RL, Bell SM, Rubin GL, Hunter RM, Ferson MJ. Improving surveillance of infectious diseases in New South Wales. Med J Aust 1991;154:828-31.

7. Allen CJ, Ferson MJ. Notification of infectious diseases by general practitioners: A quantitative and qualitative study. Med J Aust 2000;172:325-8.

8. Blogg S, Trent M. Doctors' notifications of pertussis. NS W Public Health Bull 1998;9:53-4.

9. Cagney M, MacIntyre CR, McIntyre PB, Torvaldsen S, Hanlon M. Estimating the burden of pertussis infection in children aged 5-14 years in Western Sydney Area Health Service, New South Wales, Australia: Westmead, NSW: National Centre for Immunisation Research and Surveillance, 2001.

10. Torvaldsen S, Simpson JM, McIntyre PB. Effectiveness of pertussis vaccination in New South Wales, Australia, 1996 to 1998. Eur J Epidemiol 2003;18:63-9.

11. Chen Y, Waters E, Green J. Geospatial analysis of childhood pertussis in Victoria, 1993-97. Aust N Z J Public Health 2002; 26:456-61. H 